Cahiers $d u$ MONDE RUSSE

\section{Cahiers du monde russe}

Russie - Empire russe - Union soviétique et États indépendants

$53 / 4 \mid 2012$

Varia

\title{
David Moon, The Plough that Broke the Steppe
}

\section{Alessandro Stanziani}

\section{OpenEdition \\ Journals}

Édition électronique

URL : http://journals.openedition.org/monderusse/7850

DOI : 10.4000/monderusse. 7850

ISSN : $1777-5388$

\section{Éditeur}

Éditions de l'EHESS

\section{Édition imprimée}

Date de publication : 15 décembre 2012

ISSN : 1252-6576

\section{Référence électronique}

Alessandro Stanziani, «David Moon, The Plough that Broke the Steppe », Cahiers du monde russe [En ligne], 53/4 | 2012, mis en ligne le 02 décembre 2013, Consulté le 25 septembre 2020. URL : http:// journals.openedition.org/monderusse/7850; DOI : https://doi.org/10.4000/monderusse.7850

Ce document a été généré automatiquement le 25 septembre 2020

(c) École des hautes études en sciences sociales 


\title{
David Moon, The Plough that Broke the Steppe
}

\author{
Alessandro Stanziani
}

\section{RÉFÉRENCE}

David Moon, The Plough that Broke the Steppe. Agriculture and Environment on

Russia's Grasslands, 1700-1914. Oxford : Oxford University Press, 2013, 319 p.

Cet ouvrage cherche à expliquer pourquoi, après s'être longtemps inquiétés de l'absence de terre dans les régions centrales, les Russes sont parvenus soit à adopter de nouvelles techniques agronomiques, soit à miser sur la mise en culture de nouvelles terres. Selon l'auteur, ce choix s'est fait à partir non seulement des connaissances et de leur transfert, mais aussi de la mobilité des paysans et de leur capacité d'adaptation dans de nouvelles régions. En particulier, l'ouvrage étudie l'émigration des paysans venant des régions froides du Nord vers les steppes fertiles et arides, à la fin du XVII siècle et à la fin du XIX ${ }^{e}$ siècle. Ce processus s'accompagne de l'expansion impériale russe et de l'évincement des nomades des steppes. Contrairement aux arguments des naturalistes et premiers agronomes de l'époque, les steppes n'étaient pas "vierges ", mais déjà transformées par les populations locales. Une remise en discussion de la catégorie de "nomade» est donc sous-jacente à la démarche de l'auteur. Celui-ci évoque le fait qu'en réalité, les nomades prétendus des steppes avaient déjà transformé l'environnement pour l'adapter à l'élevage, mais aussi à leur propre forme d'agriculture sédentaire. Les spécialistes agraires, puis l'historiographie russe ont donc inventé une catégorie de «nomade» et de steppes à défricher qui légitimait l'occupation et la transformation de celles-ci. Dans le cadre de cette transformation, la soha (charrue traditionnelle en bois) se révèle inadaptée au sol aride des steppes; le passage de la soha au plug venu d'Ukraine, charrue à bœuf, beaucoup plus lourde et capable de défricher la steppe, constitue un tournant décisif. La steppe est vite transformée en terre arable destinée aux céréales. 
2 Bien entendu, ce choix favorable aux céréales au détriment de l'élevage répond également à la demande croissante en blé, aussi bien à l'intérieur de la Russie que sur les marchés internationaux. Ces dynamiques entrent donc dans une histoire globale où l'expansion européenne conduit à la mise en culture des terres nord-américaines et des steppes russes. Cependant, ce n'est pas qu'une histoire à succès : d'une part, parce que les populations nomades aux États-Unis et en Russie en subirent les extrêmes conséquences ; et d'autre part parce que, surtout en Amérique du Nord, l'usage intensif des monocultures céréalière conduisit progressivement à l'épuisement des terres et au fameux Dust Bowl qui ravagea les plaines américaines dans les années 1930. Le plug russe, accompagné d'une agriculture moins intensive, écarte cette issue mais au prix d'une moindre productivité à court terme.

3 L'auteur scinde son ouvrage en trois parties : la première étudie la manière dont les paysans et les scientifiques comprennent la steppe. La deuxième analyse le changement de l'environnement tel qu'il était perçu par les acteurs de l'époque, tandis que la troisième est consacrée aux réponses apportées. La conclusion ouvre vers une analyse comparée et de longue durée qui évoque les changements et les continuités entre l'époque tsariste et l'époque soviétique en matière d'agriculture, environnement et steppes. David Moon nous avait déjà habitués à des ouvrages novateurs et depuis incontournables sur les paysans russes entre les $\mathrm{XVII}^{\mathrm{e}}$ et $\mathrm{xx}^{\mathrm{e}}$ siècles. Il ajoute une pièce remarquable de nouveauté, de solidité à la fois des sources et de leur usage, qui fait preuve de sa capacité à inscrire l'histoire russe dans une démarche à la fois d'histoire globale et d'histoire comparée. Il nous livre là une histoire environnementale intelligente qui ne cède en rien au déterminisme écologique et place l'histoire économique et sociale dans le cadre de l'histoire environnementale. 